\title{
University and College Counseling Centers' Commitment to Social Justice
}

\author{
Elizabeth M. Vera
}

Loyola University Chicago

\section{Julia C. Phillips}

Cleveland State University

\section{Suzette L. Speight}

University of Akron

Thomas M. Brounk

Washington University in Saint Louis

\section{Deidre Weathersby}

University of Illinois Urbana Champaign

\section{Rufus R. Gonzales}

Loyola University Chicago

\author{
Kathy Kordesh \\ Loyola University Chicago
}

\begin{abstract}
The aim of this study was to examine social justice activities of university and college counseling centers. Seventy center directors provided data on their centers' commitment to social justice activities, the existence and type of prevention services offered, and other indications of social justice efforts. Findings revealed that a vast majority of centers were committed to and engaged in a variety of social justice-related activities, regardless of their staff composition. Size of university was a significant predictor of only selfrated commitment to social justice.
\end{abstract}

Keywords: social justice, counseling centers, outreach, prevention 


\section{University and College Counseling Centers' Commitment to Social Justice Activities}

For over a decade, counselor education and counseling psychology have focused on the importance of infusing social justice into training, research, and delivery of services (e.g., Toporek, Lewis, \& Crethar, 2009; Vera \& Speight, 2003; 2007). Ratts, D'Andrea, \& Arredondo (2004) described social justice as the "fifth force" in counseling, helping to focus the field's attention on the ways that privilege and oppression shape the realities of clients. Social justice has been defined in a variety of ways within the literature, but most definitions characterize social justice as a vision of society where systemic inequities and inequalities have been dismantled (Bell, 1997) such that disenfranchised communities, or those who are subjected to "isms" and oppression, are represented in conversations about the allocation of resources, policy decisions, and the identification of organizational priorities (Vera \& Speight, 2003).

In discussing the ways in which a social justice commitment would influence the delivery of mental health services, Vera and Speight (2003) noted that traditional, remedial, one-on-one psychotherapy services would need to be complimented by primary prevention (e.g., universal psychoeducational programs), secondary prevention (e.g., programs aimed at "at risk" groups), advocacy efforts (e.g., representing the needs of underrepresented students to policy makers), and outreach (e.g., community-based programs). These complimentary activities as a group were identified as "nontraditional" services (Vera \& Speight). Going beyond remedial, individually focused models of treatment was also the crux of scholarship by Greenleaf and Williams (2009), who championed the importance of social justice advocacy by counselors and reaffirmed the importance of teaching the next generation of counselors the American Counseling Association's Advocacy Competencies (Lewis, Arnold, House \& Toporek, 2002).

The counseling field's commitment to social justice and action has extended not only to communitybased practice (e.g., see Evans, Kivell, Haarlammert, Malhotra, \& Rosen, 2014), but to college and university counseling center environments as well. Although the history of counseling centers included a commitment to primary prevention (Clauss-Ehlers \& Parham, 2014), many practitioners have suggested that effective services for a diverse university community will require counseling centers to change their fundamental views of counseling and expand the range of roles they are willing to play in serving the campus community (Archer \& Cooper, 1998; Jackson, 2009; Resnick, 2006; Smith, Baluch, Bernabei, Robohm, \& Sheehy, 2003). In particular, the importance of transforming views of traditional counseling (i.e., one-on-one psychotherapy) by acknowledging the impact of oppression is noted (Smith et al.). Most importantly, counseling center scholars urged the field to expand scopes of practice to include roles such as consultant and advocate, in an effort to address injustice within university and college environments (Archer \& Cooper; Resnick; Smith et al.).

A number of examples of best practices for social justice are described in the literature as models for counseling centers to emulate (e.g., Boone et al., 2011; Resnick, 2006; Smith et al., 2003). At the beginning of a center's journey toward integrating social justice, Resnick and Smith et al. suggested 
that both individuals and centers as organizations engage in activities that are focused inward. In addition to increasing self-awareness regarding one's own values and place in systemic oppression, these authors described best practices for outreach programming that provides psychoeducation on social justice (e.g., Resnick's Diversity Lunch programs focusing on prejudice reduction), gives voice to people who are often silenced or whose voices have been less valued (e.g., Smith et al.'s Lunchtime programs highlighting the voices of diverse women), or that targets underserved populations of students (e.g., Boone et al.'s Let's Talk initiative providing informal consultative services to students at various locations across campus). Finally, although not exclusive to counseling center settings, several authors described best practices for social justice outreach and prevention programming as necessitating needs assessments and/or ample opportunities for people from marginalized populations to provide input to providers regarding their social justice needs (Burnes \& Singh, 2010; Conyne, 2010; Hage \& Kenny, 2009; Hage et al., 2007; Reese \& Vera, 2007).

While these exemplars offer counseling center directors ideas for best practices, there are not yet data available on the extent to which such social justice service delivery efforts are being infused into the practice models utilized by college and university counseling centers. In fact, data on counseling center practices in general is relatively rare. One important source of data includes the National Survey of Counseling Center Directors, originating at the University of Pittsburgh, but now sponsored and implemented by the Association of University and College Counseling Center Directors (AUCCCD; Gallagher, 2012). This survey is used to collect data on counseling center personnel, policies and practices. These data were used to illustrate that although counselors in college and university counseling center settings engaged in career counseling a majority of the time in 1970, by 2006, directors reported that $88 \%$ of counseling services were personal in nature and that student concerns were increasingly severe (Gallagher, 2012).

With respect to social justice initiatives, the 2013 AUCCCD Annual Survey (Reetz, Barr, \& Krylowicz, 2013), utilized two questions to identify any prevention activities associated with suicide and with alcohol use and one question asked what type of outreach services were offered to each of a variety of underserved groups of students. This information is useful to directors to generate ideas for such activities, but does not inform the field about the incidence of these prevention and outreach activities in counseling centers overall.

Such data would be valuable for a number of reasons. First, understanding the extent of college and university counseling centers' social justice activities is important for its own sake, particularly for informing future development and improvement of programs and initiatives that contribute to a just society and campus community. Data will also be useful for assisting administrators of counseling centers to make the case for engaging in such services in times of heavy demand for traditional clinical services. Data are also particularly valuable for informing students about opportunities to receive training and ultimately find employment in settings that encourage non-traditional service delivery. Students want to engage in social justice practice and express a strong desire for hands-on training in agency settings to learn how to engage in non-traditional service delivery effectively (Burnes \& Singh, 2010; Singh et al., 2010). Students' training in social justice, particularly in skills-based activities, is 
uneven at best as evidenced by a study of multicultural course syllabi in CACREP-accredited counseling and APA-accredited counseling psychology programs (Pieterse, Evans, Risner-Butner, Collins, \& Mason, 2009) and by student responses in a qualitative study of social justice training experiences in counseling psychology doctoral programs (Singh et al., 2010). Clearly, a need exists for social justice training (Vera \& Speight, 2007) and more information about where such training exists would be valuable.

The purpose of the current study was to explore the degree and type of social justice initiatives in college and university counseling centers. Specifically, the investigation was based on several research questions. First, how do university and college counseling centers enact their commitment to social justice on their campuses? Second, to what extent is prevention, outreach, and/or advocacy utilized as part of this commitment? Third, what factors predict counseling centers' commitment to social justice, value of outreach, and the number of hours of outreach they offer?

\section{Method}

\section{Participants}

Directors of university and college counseling centers were contacted via email to participate in an online survey. We obtained email addresses from the list of names from the Association of University and College Counseling Center Directors (AUCCCD). The stated membership of AUCCCD, according to the organization's 2013 Director's Survey Report (Reetz et al., 2013) is 762 members. Seventy surveys were completed anonymously by participants who were members of this organization. While it is unknown if every potential participant viewed the email invitation, our return rate was calculated to be approximately $10 \%$. No personal demographic data were collected on the Directors who responded to the survey to ensure anonymity of responses. Descriptive data were collected on the center's demographic characteristics (e.g., FTEs, gender of the staff members) and the university's size, all of which are summarized in Table 1.

\section{Survey}

In order to ascertain how important social justice activities were and how frequently outreach and prevention activities occurred, the authors devised an on-line survey in order to make data collection as user friendly as possible. The survey link was embedded in an email sent to members of AUCCCD. In the process of creating the questions, we consulted with 3 university counseling center outreach coordinators to make sure that the wording of the questions was appropriate and that the survey itself was not too cumbersome. Based on the feedback we received, the survey contained some definitions of terms. For example, we gave examples of underrepresented cultural groups in parentheses when we asked about how well represented staff members were in terms of historically underrepresented groups. We also gave short definitions of primary and secondary prevention in parentheses for clarification. We did not provide definitions of all terms, however. For example, we did not explicitly 
define outreach. We also did not define social justice when we asked directors to estimate their center's commitment to providing outreach and their commitment to social justice relative to other centers. These questions were the final questions on the survey, however. Thus, respondents would have potentially been prompted to connect social justice commitments to previous questions about prevention, outreach, and advocacy for underrepresented student groups. In order to make the survey as face valid as possible, we edited the survey content per the advice of our outreach experts until they all were satisfied with the content. Given that most of our areas of interest were assessed with single item questions, we were unable to collect traditional reliability data on our survey scores.

\section{Procedure}

Participants were directed to a website that contained a 30 question survey created by the authors that asked about the center's commitment to social justice activities and the importance of outreach in their mission, the extent to which the center offered primary and secondary prevention services, the frequency with which outreach efforts occurred, whether student advocacy efforts existed, the nature of liaison relationships with other student affairs units, and the use of mechanisms for obtaining feedback from the student body. In addition, the survey contained questions about the size and characteristics of the staff, the existence of a dedicated outreach coordinator, whether the center was stand-alone or integrated into a general Health or Wellness Center, and the training opportunities at the center. The response set to the survey items was a combination of multiple-choice (e.g., size of the university), yes-no (e.g., whether an Outreach coordinator was on staff), Likert scale (e.g., rating of center's commitment to social justice) and fill-in-the-blank (e.g., the number of FTE staff members). The survey questions are contained in Appendix A. The survey took less than 20 minutes to complete and participants were offered an opportunity to win one of three $\$ 50$ Amazon gift cards in appreciation for their time.

\section{Results}

Participants shared descriptive data about the centers they directed and the size of the student body that their center served. Forty-one percent of the participating centers served a student body less than $5,000,31 \%$ served student bodies that ranged in size from 5,000 to 15,000 and $28 \%$ served student bodies over 15,000 . The majority of centers were stand-alone counseling centers (56\%), with $24 \%$ reporting that they were fully integrated into Health or Wellness Centers and $20 \%$ reporting that they were partially-integrated.

In terms of staff size, the mean number of FTE's was 7.35 ( $\mathrm{sd}=7.25)$ with a range of 1 to 40 . Diversity of staff members was reported to be the following: the mean percentage of women was $50 \%$, the mean percentage of ethnic minority staff members was $19 \%$, the mean percentage of gay, lesbian, bisexual, or transgender staff was less than $10 \%$, religious minority staff members were less than $10 \%$, and staff members with disabilities constituted less than $10 \%$ on average. 
In addition to the FTE staff resources that counseling centers have, we inquired about the existence of trainees that participate in providing services to clients. Thirty percent of participating centers had pre-doctoral psychology internship programs. However, training students was a part of the mission of all the participating centers and on average, 4 trainees a year were involved in practica or externships.

Regarding the ways in which counseling centers might go about creating feedback loops between themselves and their student constituents, we asked about the extent to which two mechanisms were utilized. Participants reported that student advisory groups were infrequently utilized $(25 \%)$ and that only a small percentage of centers (30\%) regularly assessed the mental health needs of the general student body.

Forty-two percent of the participating centers reported that they had a designated Outreach Coordinator position within their staff. When this position existed, the average percentage of time per week allocated to outreach activities was $28.6 \%$. The mean number of hours per week that centers offered outreach and prevention activities was 8.6 hours.

With respect to the center's commitment to social justice, the majority of respondents (80\%) rated their commitment as equal to or greater than the commitments of their peer institutions. Only $19 \%$ of the respondents reported that their commitment to social justice was "marginal" or "less committed" than their peer institutions.

With respect to whether and what kinds of prevention, outreach, and advocacy are implemented by the Center, the vast majority of respondents noted that outreach was central or very important to their mission (87\%). Additionally, $90 \%$ reported that they regularly offered primary prevention services and $65 \%$ reported that they offered secondary prevention services.

In terms of types of outreach activities offered by the participating centers, the most frequent type of primary prevention activities were problem-focused prevention such as anxiety, substance abuse, suicide, and eating disorders prevention programs. The second most commonly reported primary prevention activities were well-being and health promotion programs such as self-care, mindfulness, or gratitude promotion programs. The third most commonly reported type of primary prevention activities were skill-building programs such as relaxation training, time management, study skills, and social skills training. Secondary prevention services were also reported as examples of outreach activities. Risk-focused services that were most frequently listed included population specific programs for students of color, LGBTQ students, international students, and first-generation college students. The second most common type of secondary prevention services offered were problemspecific such as programs on drugs and alcohol abuse, sexual assault, and trauma.

Sixty-nine percent of centers also reported that they advocated for student groups at their colleges or universities. The group of students named most frequently in response to the question of "for which groups of students do you regularly advocate" was LGBT students, followed by students of color, veterans, international students, and students with disabilities. When advocacy activities occurred, the 
most common target of advocacy was either university administrators or specific departments/organizations on campus.

Sixty percent of participating centers also reported that they offered community-level services as evidence of their commitment to social justice. The majority of services were either prevention or consultation services. Examples of the community services offered included activities such as mental health screening fairs, professional development sessions, and crisis consultation.

Several questions inquired about the liaison relationships with whom centers worked. The vast majority (i.e., 95\%) of respondents noted that they had formal and informal liaison relationships with other units on campus that facilitated outreach and prevention efforts. Liaison relationships with whom Counseling Centers worked regularly and effectively in terms of providing outreach and prevention services included (in their order of frequency): Residence Life, followed by the Office of the Dean of Students, other general Student Affairs Units, Diverse Student Offices, Disability Services, Health Centers, the Athletic Department, Academic Departments, and Career Services. Tables 2 and 3 contain summaries of the examples of prevention activities and liaison relationships provided by participants.

Finally, three analyses of variance (ANOVA) were conducted to determine what factors, if any, would predict counseling centers' commitment to social justice activities. Specifically, we were interested in whether size of university would be significantly related to commitment to social justice activities, the centrality of outreach to the mission, and the number of weekly hours of outreach offered. Thus, we used size of university as the independent variable (broken down into less than 5,000, 5,000-15,000, and larger than 15,000 students) and the dependent variables of commitment to outreach, hours of outreach offered per week, and commitment to social justice.

In order to determine our ability to run these analyses given our sample size, a power analysis was conducted. With our sample size of 70 , using a .05 alpha level, our ability to detect moderate effect sizes is .78 , which is close to the .80 standard of acceptable power recommended by Cohen and Cohen (1983).

Size of university was a significant predictor of one outcome: the degree to which the center was committed to social justice $(F(2,68)=3.15, p<.05)$. Size of university approached significance in centrality of outreach to mission $(F(2,68)=2.79, p<.10)$ and hours of outreach offered per week $(F(2$, $68)=2.55, p<.10)$. Post-hoc examination of means revealed that counseling centers at larger universities expressed the greatest commitment to social justice but did not report a greater degree of focus on outreach, or a greater number of hours of outreach per week compared to counseling centers at medium or smaller universities. Small universities reported the overall fewest hours per week of outreach activities, which may indicate a trend, but the significance of this difference did not reach the .05 level. A table of the means, standard deviations, and results of the ANOVAs is offered in Table 4. 
In addition to the size of the university, we also examined whether specific types of diversity of staff (i.e., the percentage of staff who were members of ethnic minority and LGBT groups) were related to the centrality of outreach as part of the mission, the hours of outreach offered per week, and the commitment to social justice. Correlation coefficients were calculated among these variables and it was determined that ethnic diversity of staff was not significantly related to outreach centrality $(r=-$ $.207, p>.05)$, hours of outreach $(r=.181, p>.05)$, or commitment to social justice $(r=.136, p>.05)$ nor was sexual orientation diversity related to outreach centrality $(r=-.119, p>.05)$, hours of outreach $(r=$ $.175, p>.05)$ or commitment to social justice $(r=.132, p>.05)$.

\section{Discussion}

This exploratory study of the ways in which university and college counseling centers identify and operationalize their commitments to social justice adds several interesting findings to the literature. First, regardless of staff composition, university and college counseling centers in this study are demonstrating observable commitments to social justice activities namely in the frequency with which they offer prevention, outreach, and advocacy on behalf of their student communities. This commitment is consistent with counseling centers' historical roots in primary prevention activities (Clauss-Ehlers \& Parham, 2014) and calls for college and university counseling centers to engage in social justice activities in the future (e.g., Resnik, 2006; Smith et al., 2003).

Although not all participating centers had designated outreach coordinators, the majority did commit staff hours to such activities. The wide variety of prevention activities being offered also suggests that counseling centers are responding to an array of risky behaviors and population-specific needs. In addition to traditional types of prevention services one might expect counseling centers to offer such as alcohol and drug abuse prevention, suicide prevention, or sexual assault prevention, many centers have embraced a health promotion approach to primary prevention in the work they do, which aligns with the literature's recommendations for best practices (Hage et al., 2007).

Another interesting finding was that the only significant predictor of commitment to social justice was size of the university. While hours of outreach offered per week approached significance based on size of the university, we must conclude that counseling centers housed in larger universities did not in fact offer more outreach than their smaller counterparts. While perhaps larger universities are better positioned to offer a wider array of services, they also may have greater in-office therapy needs for their students. The fact that centers in smaller universities reported the fewest hours per week of outreach is not necessarily surprising and is consistent with literature that documents the resource/staffing issues that face smaller university and college counseling centers (Vespia, 2007). These findings would suggest that university and college counseling centers, if given ample staff resources, have the flexibility and autonomy to determine how staff spend their time and how they engage the student body. 
There are two areas for constructive feedback that might arise from these findings. First, in the area of constituent engagement and dialogue, given that only 25 to $30 \%$ of centers had a mechanism for doing so, an argument could be made for centers to be more active in soliciting feedback from their student bodies as a whole, as opposed to solely from the students who seek services from them. Efforts to engage with underrepresented student groups were not as evident via assessing mental health needs of student communities and utilizing student advisory groups, despite the fact that those are considered to be best practices within the field of prevention and outreach (e.g., Burnes \& Singh, 2010; Conyne, 2010; Hage \& Kenny, 2009; Hage et al., 2007; Reese \& Vera, 2007). It is possible that counseling centers utilized other mechanisms for obtaining regular feedback from constituent groups that we failed to include in the survey, but even in the open-ended areas of the questionnaire, no such processes were introduced. Second, few examples of systemic interventions related to policy change were provided by directors when asked about community level social justice activities. Although $60 \%$ of directors indicated that community level activities occurred, the majority of these activities were programs to prevent mental health problems or promote professional development for colleagues, or to provide consultation regarding crises. Thus, it is unclear how counseling centers are contributing to systems level change related to social injustice. Examples of such systems level changes might be grassroots efforts to change governance structures to foster empowerment of disempowered constituencies at the university, or to redistribute resources in ways that promote social justice. Future research should attempt to identify effective ways that counseling centers might contribute to systemic change on campuses through policy work or systemic level interventions.

\section{Limitations}

Two limitations of this study are its sample size and a presumed self-selection bias among participants. Although our sample size may limit the generalizability of our results, the findings of this study paint a positive picture of the social justice efforts of university and college counseling centers around the U.S. With respect to selection bias, directors of centers who are actively committed may have been more likely to take the time to participate in the study to showcase the good work they are doing. Directors of centers who are either not as committed or who are too under-resourced to provide services beyond psychotherapeutic services may have been less inclined to participate in this study. Therefore, we have likely documented an overestimation of the extent to which counseling centers are committed to social justice and its companion activities of outreach, prevention, and advocacy.

Additionally, we did not define the term "social justice" for our participants and instead relied on their own definitions of this construct in the questions in which we referred to it. It is possible that directors had different ideas about what such a commitment would look like or whether outreach and prevention or advocacy activities would be reflective of such a commitment. Although we asked an open-ended question regarding additional community level interventions that centers engaged in, we also did not ask about other types of social justice activities at the systemic or policy level. Finally, our survey was examined for its face validity and content validity by several experts in the field, but we did not have multiple items that measured several of the constructs which prohibited reliability analyses from being conducted. 


\section{Implications for Training}

Assuming that these data represent to some degree the level of commitment that university and college counseling centers have to social justice activities, the findings suggest that there are in fact opportunities for students to be trained in non-traditional service delivery models and for new professionals to find employment where such skills might be desirable. Students express a desire for such experience and training (Singh et al., 2010) and scholars emphasize the importance of opportunities for students committed to social justice to get practical opportunities to hone their skills (Burnes \& Singh, 2010; Pieterse et al., 2009). Additionally, such training is consistent with recommendations for training health service psychologists (Health Service Psychology Education Collaborative, 2013) and with accreditation guidelines for CACREP (CACREP, 2009). As such, these data tentatively represent good news indeed.

It may be important for counseling centers that are providing such diverse training opportunities to be more self-promoting when it comes to recruiting trainees given the level of interest that students have in being able to find arenas to hone their prevention, outreach, and advocacy skills. Anecdotally, it is not unusual for students to mistakenly dismiss university counseling centers as places that serve only privileged populations with developmental concerns. Whereas this characterization may have been more true in the past, the current situation is one in which many opportunities might exist to work with marginalized people and to engage in social justice efforts outside of traditional individual counseling relationships (e.g., Archer \& Cooper, 1998; Clauss-Ehlers \& Parham, 2014; Jackson, 2009; Resnick, 2006; Smith et al., 2003).

\section{Implications for Future Research}

Given the conversations happening in our field about social justice and its relevance, its important for future researchers to contribute to efforts to operationalize the construct of social justice in university and college counseling centers. Furthermore, developing a measure of social justice activities within campus settings and providing validation evidence for such a measure would create the ability for researchers to uniformly quantify the concept of "social justice commitment." This measure would provide a theoretical framework or conceptual map to guide university and college counseling centers as they evaluate their own commitment to social justice. Examining vision and mission statements in light of this operational definition would better ensure a clearinclusion of a commitment to social justice in the statements. An operational definition would assist practitioners in counseling centers to better understand how they need to modify servicesand/or change their philosophical outlooks to better ensure social justice on their campuses and in their communities. If counseling centers are committed to social justice, articulating this pledge clearly in mission statements would allow students to make better training decisions and more easily identify the centers where justice related activities are available.

In a more general sense of quantifying the variety of prevention, outreach, or advocacy services, it would be highly beneficial to monitor the breadth of services and training activities that are available within university and college counseling center environments more systematically. The AUCCCD 
Annual Survey (e.g., Reetz et al., 2013) would be a convenient vehicle for doing so. Currently, the Annual Survey asks two questions about prevention (i.e., (1) if you offer Suicide Prevention services, what interventions are used and (2) if you offer Substance Abuse Prevention services, what interventions are used) and asks qualitative questions about what outreach efforts exist for a variety of student populations (e.g., Ethnic minority, LGBT, International, Students with Disabilities, etc.). There also appears to be a question about whether an Outreach Coordinator position exists, but the 2013 Report available to the public did not report data on this category. Having these data available regularly would enable counseling centers to showcase the work that they do to potential trainees, the student bodies of their campuses, and their administrators. This latter group influences the resources made available to counseling centers, thus advocacy for the center is often an important component of Directors' jobs.

To this point, it is also important for counseling centers to find ways to document the benefits of outreach, prevention, and advocacy services that they provide. Evaluating these types of services is often more challenging than evaluating psychotherapeutic efforts (Romano, 2014; Vera, 2000), largely because symptom remission is not necessarily the best indicator of effectiveness. Evaluating prevention and outreach might be better served in several ways.

First, by using population-wide data that are obtainable through regular assessments of the mental health of student bodies (e.g., using the National College Health Assessment II [American College Health Association, 2014]), it might be possible to document trends in for example, whether implementing a primary prevention program on sexual assault or binge drinking reduces studentreported incidents over time. Second, having student advisory groups to understand the needs and perceptions of often harder-to-reach student communities (e.g., transgender students) could create a vehicle for dialogue and better understanding, such that outreach and prevention programs could be driven by this information and first-hand understanding of the community. Third, for students who attend outreach and prevention events, it would be beneficial to evaluate whether not only their own knowledge and behaviors will change as a result of the intervention, but also whether their intent to potentially intervene with peers might increase, or if their willingness to consider pursuing therapeutic services for themselves or loved ones might increase due to their new awareness. This information might be of value in documenting that outreach efforts are actually effective in reaching students who would otherwise not seek services at the counseling center.

The benefit of documenting the value of both traditional therapeutic services and less-traditional outreach and prevention services is an important aspect of keeping university and college counseling center services a top priority within the Student Affairs arena. The potential for these services to be outsourced or subsumed into Health and Wellness centers, often to cut budgets, has the potential to eliminate a valuable and unique approach to student mental health that is embedded in counseling center history and culture (Brown, Perez, \& Reeder, 2007).

Another potential idea for future research would be to examine the social justice commitments of university and college counseling centers that are not affiliated with AUCCCD or to examine the efforts of institutions that are not as well-represented within the organization such as community 
colleges. Community colleges often have higher enrollments of underrepresented students such as first-generation students, immigrant students, low-income students, and/or students of color and the services they offer may be less similar to those offered by their four-year counterparts. In the pursuit of identifying the range of ways in which social justice commitments are enacted within higher education environments, the perspectives of community college centers would be highly beneficial to have in the literature.

In an era where the mental health needs of college students are becoming more intense and the incidence of more severe mental health problems are reaching historically high levels (Gallagher, 2012; Locke et al., 2012), university and college counseling center staff have a daunting set of challenges ahead of them. The difficulty that many counseling centers have in meeting their intake requests is an argument, perhaps, against adding services that are potentially superfluous. Taking a devil's advocate perspective, one could argue the case that until counseling centers have more staff and resources, asking them to "do more" than try to function with as short of a waiting list as possible is unfair. However, as Albee (2000) noted, solely providing remedial psychotherapeutic services does nothing to reduce incidents of new cases. Hence, in theory, offering more proactive preventive outreach might have the long term effect of reducing waiting lists by getting help to people before they need it. Additionally, initiatives taken by counseling centers to reduce social injustices in the campus community may improve mental health and educational outcomes for students who are currently adversely impacted by minority stress. This important possibility, combined with the fact that the mental health field is embracing social justice as a part of its mission, makes the availability of outreach, prevention, and advocacy an important aspect of the identity of counseling centers. Having such a commitment to these services will also position counseling centers to be on the cutting edge of practice opportunities for students and professionals who desire job place settings where social justice values and related skills will be assets.

\section{Author Contact Information}

Correspondence regarding this article should be directed to: Elizabeth Vera, Loyola University Chicago, $820 \mathrm{~N}$. Michigan Avenue, Chicago, IL 60645, evera@luc.edu

Elizabeth Vera is a Professor of Counseling Psychology in the School of Education at Loyola University Chicago. Her scholarship includes training and social justice, prevention, and promoting well-being in urban, ethnic minority youth. Julia C. Phillips is an Associate Professor at Cleveland State University and the Co-Director of Training of CSU's counseling psychology doctoral program. Prior to joining the faculty at CSU, she enjoyed a long career as a psychologist in university counseling centers. Her research interests include professional issues, training, and diversity. Suzette L. Speight is an Associate Professor of Psychology and Co-Director of Training for the Collaborative Program in Counseling Psychology at The University of Akron in Akron, Ohio. Her research and scholarly interests include the psychological effects of oppression, mental health and African American women, identity development, Africancentered Psychology, multicultural competence, and social justice and psychology. Thomas M. Brounk is the Director of Mental Health Services at Washington University in Saint Louis. He received his Ph.D in counseling psychology from The Ohio State University and is an active member of the Association of University and College Counseling Center Directors. Deidre Weathersby is a staff psychologist at the University of Illinois Counseling Center. She is also Chair of 
the University's African American Student Outreach organization- SANKOFA. Her research and practice interests include prevention, outreach, and advocacy. Rufus R. Gonzales is a Clinical Assistant Professor and the Coordinator for Clinical Training in the Counseling Psychology programs at Loyola University Chicago. He teaches courses in counseling skills, practicum, and human development. He was formerly a staff therapist and Assistant Director for Clinical Training at DePaul University Counseling Services. Kathy Kordesh is a post-doctoral fellow. She is a graduate of the doctoral program at Loyola University Chicago. Her scholarly interests include multicultural competencies, White racial identity development, and social justice.

\section{References}

Albee, G. W. (2000). Commentary on prevention and counseling psychology. The Counseling Psychologist, 28, 845-853. doi: 10.1177/0011000000286006

American College Health Association. (2014). National college health assessment II: Reference group executive summary spring 2014. Hanover, MD: American College Health Association. Retrieved from http://www.acha-ncha.org/docs/ACHA-NCHAII_ReferenceGroup_ExecutiveSummary_Spring2014.pdf

Archer, J. Jr., \& Cooper, S. (1998). Counseling and mental health services on campus: A handbook of contemporary practices and challenges. San Francisco: Jossey-Bass.

Bell, L. (1997). Theoretical foundations for social justice education. In M. Adams, L. Bell, \& P. Griffin (Eds.), Teaching for diversity and social justice (pp. 3-16). New York: Routledge.

Boone, M. S., Edwards, G. R., Haltom, M., Hill, J. S., Liang, Y., Mier, S. R., ... \& Yau, Y. T. (2011). Let's Talk: Getting out of the counseling center to serve hard-to-reach students. Journal of Multicultural Counseling and Development, 39, 194-205.

Brown, S. D., Perez, R. M., \& Reeder, B. L. (2007). The costs and benefits of merging counseling centers with student health services: Perceptions of the experiences. Journal of College Student Psychotherapy, 22, 3-16. doi: 10.1300/J035v22n01_02

Burnes, T. R., \& Singh, A. A. (2010). Integrating social justice training into the practicum experience for psychology trainees: Starting earlier. Training and Education in Professional Psychology, 4, 152-163. doi: 10.1037/a0019385

Cohen, J. \& Cohen, P. (1983). Applied statistical analysis for the behavioral sciences. Hillsdale, NJ: Erlbaum.

Council for Accreditation of Counseling and Related Educational Programs. (2009). CACREP Standards. Retrieved from http://www.cacrep.org/wpcontent/uploads/2013/12/2009-Standards.pdf

Clauss-Ehlers, C. S., \& Parham, W. D. (2014). Landscape of diversity in higher education: Linking demographic shifts to contemporary university and college counseling center practices. Journal of Multicultural Counseling and Development, 42, 69-76. doi: 10.1002/j.2161-1912.2014.00045.x

Conyne, R. K. (2010). Prevention program development and evaluation: An incidence reduction, culturally relevant approach. Thousand Oaks, CA: Sage. 
Evans, S. D., Kivell, N. Haarlammert, M., Malhotra, K., \& Rosen, A. (2014). Critical community practice: An introduction to the special section. Journal of Social Action in Counseling and Psychology, 6, 1-15. Retrieved from http://www.psysr.org/jsacp/Evans-v6n1-14_115.pdf

Gallagher, R. P. (2012). Thirty years of the National Survey of Counseling Center Directors: A personal account. Journal of College Student Psychotherapy, 26, 172-184. doi: $10.1080 / 87568225.2012 .685852$

Greenleaf, A. T. \& Williams, J. (2009). Supporting social justice advocacy: A paradigm shift toward an ecological perspective. Journal for Social Action in Counseling and Psychology, 2, 1-14. Retrieved from http://www.psysr.org/jsacp/greenleaf-v2n1-09_114.pdf

Hage, S. M., \& Kenny, M. E. (2009). Promoting a social justice approach to prevention: Future directions for training, practice, and research. Journal of Primary Prevention, 30, 75-87.

Hage, S. M, Romano, J. L., Conyne, R. K., Kenny, M., Matthews, C., Schwartz, J. P., \& Waldo, M. (2007). Best practice guidelines on prevention practice, research, training, and social advocacy for psychologists. The Counseling Psychologist, 35, 493-566. doi: 10.1177/0011000006291411

Health Service Psychology Education Collaborative. (2013). Professional psychology in health care services: A blueprint for education and training. American Psychologist, 68, 411426. doi: $10.1037 / \mathrm{a} 0033265$

Jackson, K. (2009). The use of family therapy within a university counseling center. Journal of College Student Psychotherapy, 23, 253-261. doi: 10.1080/87568220903163983

Lewis, J., Arnold, M. S., House, R. \& Toporek, R. (2002). ACA Advocacy Competencies. Retrieved from http://www.counseling.org/Publications/

Locke, B. D., Bieschke, K. J., Castonguay, L. G., \& Hayes, J. A. (2012). The Center for Collegiate Mental Health: Studying college student mental health through an innovative research infrastructure that brings science and practice together. Harvard Review of Psychiatry, 20, 233-245. doi: 10.3109/10673229.2012.712837

Pieterse, A. L., Evans, S. A., Risner-Butner, A., Collins, N. M., \& Mason, L. B. (2009). Multicultural competence and social justice training in Counseling Psychology and Counselor Education: A review and analysis of a sample of multicultural course syllabi. The Counseling Psychologist, 37, 93-115. doi: 10.1177/0011000008319986

Ratts, M., D'Andrea, M., \& Arredondo, P. (2004). Social justice counseling: "Fifth force" in counseling field. Counseling Today, 47, 28-30.

Reese, L. E., \& Vera, E. M. (2007). Culturally relevant prevention: The scientific and practical considerations of community-based programs. The Counseling Psychologist, 35, 763778. doi: $10.1177 / 0011000007304588$ 
Reetz, D. R., Barr, V., \& Krylowicz, B. (2013). The Association of University and College Counseling Center Directors annual survey. Retrieved from http://files.cmcglobal.com/AUCCCD_Monograph_Public_2013.pdf

Resnick, J. L. (2006). Strategies for implementation of the Multicultural Guidelines in university and college counseling centers. Professional Psychology: Research and Practice, 37, 14-20. doi: 10.1037/0735-7028.37.1.14

Romano, J. (2015). Prevention psychology: Enhancing personal and social well-being. Washington, DC: American Psychological Association.

Singh, A. A., Hofsess, C. D., Boyer, E. M., Kwong, A., Lau, A. S. M., McLain, M., \& Haggins, K. L. (2010). Social justice and counseling psychology: Listening to the voices of doctoral trainees. The Counseling Psychologist, 38, 766-795. doi: 10.1177/0011000010362559

Smith, L., Baluch, S., Bernabei, S., Robohm, J., \& Sheehy, J. (2003). Applying a social justice framework to college counseling center practice. Journal of College Counseling, 6, 3-13.

Stone, G. L., Vespia, K. M., \& Kanz, J. E. (2000). How good is mental health care on college campuses? Journal of Counseling Psychology, 47, 498-510.

Toporek, R. L., Lewis, J. A., \& Crethar, H. C. (2009). Promoting systemic change through the ACA Advocacy Competencies. Journal of Counseling \& Development, 87, 260-268.

Vera, E. (2000). A recommitment to prevention work in counseling psychology, The Counseling Psychologist, 28, 829-837. doi: 10.1177/0011000003031003001

Vera, E. M., \& Speight, S. L. (2003). Multicultural competence, social justice, and counseling psychology: Expanding our roles. The Counseling Psychologist, 31, 253-272. doi: 10.1177/0011000000286004

Vera, E. M., \& Speight, S. L. (2007). Advocacy, outreach, and prevention: Integrating social action roles in professional training. In E. Aldarondo (Ed.), Advancing social justice through clinical practice (pp. 373-390). Mahwah, NJ: Lawrence Erlbaum.

Vespia, K. M. (2007). A national survey of small college counseling centers: Successes, issues, and challenges. Journal of College Counseling, 22, 17-40. doi: 10.1300/J035v22n01_03 
Table 1. Description of participating counseling centers

\begin{tabular}{ll}
\hline Size of University & \\
$\quad$ Less than 5000 & $41 \%$ \\
$5000-15000$ & $31 \%$ \\
Over 15000 & $28 \%$ \\
Independent vs. Integrated & \\
$\quad$ Stand Alone Center & $56 \%$ \\
$\quad$ Partially Integrated & $20 \%$ \\
$\quad$ Fully Integrated & $24 \%$ \\
Centers with Internship Program & $30 \%$ \\
Diversity of Staff Mean Percentage & \\
Women & $50 \%$ \\
$\quad$ Ethnic Minority & $19 \%$ \\
$\quad$ Gay, Lesbian, Bisexual & $<10 \%$ \\
Religious Minority & $<10 \%$ \\
Disability & $<10 \%$ \\
Mean Staff Size (FTE) & $7.35(\mathrm{sd}=7.25)$ \\
Mean Total Staff doing Outreach/Prevention & 5.23 \\
Centers with Outreach Coordinator Position & $42 \%$ \\
Outreach Coordinator FTE & $28.6 \%$ \\
Centers that Formally Assess Student Needs & $30 \%$ \\
Centers that Have Student Advisory Groups & $25 \%$
\end{tabular}

Table 2. Liaison relationship partners and primary prevention activities

\begin{tabular}{ccll}
\hline Liaison Outreach Relationships $(\mathrm{N}=101)$ & & & \\
Residence Life & 23 & International Student & 6 \\
Dean of Students & 16 & Diverse Student Office & 6 \\
Student Affairs & 10 & Athletic Department & 5 \\
Health Center & 8 & Academic Departments & 5 \\
Disability Services & 8 & Career Services & 5 \\
Campus Safety & 7 & Veteran Services & \\
& & & \\
Primary Prevention Activities $(\mathrm{N}=189)$ & & Skill Building & 23 \\
Problem Specific Prevention & 117 & Relaxation & 7 \\
Anxiety Prevention & 45 & Time Manage & 6 \\
Substance Abuse & 23 & Study Skills & 6 \\
Eating Disorders & 14 & Social Skills & 6 \\
Suicide Prevention & 11 & & \\
Other & 23 & & \\
Well-being \& Health Promotion & 49 & & \\
Self-care & 18 & & \\
Mindfulness & 17 & & \\
Gratitude & 5 & \\
Sleep & 4 &
\end{tabular}


Table 3. Secondary prevention activities

\begin{tabular}{cl}
\hline Secondary Prevention Activities $(\mathrm{N}=53)$ & 28 \\
Population Specific & 7 \\
Students of Color & 7 \\
LGBTQ & 8 \\
International & 4 \\
First Generation & 2 \\
Other & 14 \\
Problem Specific & 2 \\
Drug and Alcohol & 2 \\
Sexual Assault & 4 \\
Body Image & 2 \\
Trauma & 4 \\
Other & 11
\end{tabular}

Table 4. Differences in importance of outreach to students, hours of outreach (per week), and commitment to social justice activities by size of university or college

\begin{tabular}{lccccccccc}
\hline Dependent Variable & \multicolumn{2}{c}{ Small $(\mathrm{n}=27)$} & \multicolumn{2}{c}{ Medium $(\mathrm{n}=21)$} & \multicolumn{2}{l}{ Large $(\mathrm{n}=19)$} & $\mathrm{F}(2,68)$ & $\mathrm{p}$ \\
& $\mathrm{M}$ & $\mathrm{SD}$ & $\mathrm{M}$ & $\mathrm{SD}$ & $\mathrm{M}$ & $\mathrm{SD}$ & & \\
& & & & & & & & & \\
& 1.96 & .587 & 1.62 & .669 & 1.58 & 1.75 & 2.79 & .07 \\
& 2.05 & 1.29 & 8.00 & 13.58 & 6.28 & 5.95 & 2.55 & .09 \\
Outreach to students & .832 & 2.95 & .669 & & 3.53 & .905 & 3.15 & .05
\end{tabular}

Appendix A. Survey ltems

Dear Counseling Center Director:

We are surveying counseling centers around the country to see how the centers attempt to meet the needs of historically underserved students. The following questions assess basic characteristics of your university, your counseling center, and specific programs and procedures designed to meet the needs of your students. This survey should take no more than 20 minutes to complete.

1. Size of university

less than 5000

$5000-10000$

$10000-15000$

15000 to 20000

20000-25000

25000 to 30000

30000-40000

40000-50000

2. Is counseling center stand alone or integrated with other wellness/health services?

Stand alone

Partially Integrated 
Fully Integrated

3. Regarding your mental health counseling and psychiatric staff, including post-docs, how many FTEs do you have (not including trainees)?

4. What is the FTE of staff at your Counseling Center, including post docs, who provide outreach and prevention programming for your university (not including trainees)?

5. Do you have a formal pre doctoral psychology internship program? Yes/No

6. Is it APPIC affiliated or APA accredited? APPIC affiliated APA accredited Both Neither N/A

7. How many FTE trainees do you have annually, if applicable (not including post docs)? in Practicum in Internship as Graduate Assistants Undergraduate Peer Educators

8. What percentage of your staff (not trainees) represent a historically underrepresented group (e.g., ethnic minority group, gay, lesbian, bisexual, transgendered, religious minority, persons with disabilities) Women Ethnic Minority GLBT Religious Minority Persons with Disabilities Other

9. Does your counseling center assess the mental health needs of the student body as a whole at your university on a regular basis? Yes/No

10. Do you have a student advisory group? Yes/No

11. If applicable, how often do you meet with the student advisory group?

12. Which of the following best characterizes the nature of your interactions with other units in student affairs?
a. Formal liaison relationships
b. Informal consultative relationships
c. Minimal interaction or relationship

13. Please identify any units with which you have formal liaison relationships.

14. With which units do you have the most effective relationships?

15. To what degree do you provide outreach to students?

a. It is central to our mission and we provide outreach on a weekly basis.

b. It is important to our mission \& we provide outreach on a monthly basis.

c. It is peripheral to our mission \& we provide outreach several times a semester.

d. It is not part of our mission and we rarely provide outreach.

16. Do you have a dedicated outreach coordinator position(s)? Yes/No 
17. If so, what is the FTE percentage of time that your outreach coordinator devotes to coordinating outreach?

18. On average, how many hours of outreach per week does the counseling center provide to the university community?

19. Do you engage in primary prevention (i.e., universal psychoeducation)? An example of primary prevention is mindfulness-based stress reduction. Yes/No

20. If so, what types?

21. Do you engage in secondary prevention (i.e., aimed at specific groups at higher risk for an issue)? An example of secondary prevention is retention initiatives for African American men. Yes No

22. If so, what types?

23. Do you advocate for any particular groups of students within the university (e.g., students of color, LGBTQ students, sexual assault survivors, veterans)? Yes/No

24. If so, which groups of students and to whom do you regularly advocate?

25.Are there other ways that the $\mathrm{CC}$ attempts to meet the needs of underrepresented or marginalized students at the university?

26. Are there other ways that the Counseling Center attempts to meet the needs of underrepresented or marginalized groups at the university?

27. Are there other community-level types of interventions that your CC provides? Yes/No

28. If so, what kinds of interventions?

29. How would you describe your CC's perspective on social justice?

30. If you had to quantify your counseling center's commitment to social justice/inclusivity at your university, would you say you are:

1 Marginally committed

2 Committed but not as much as other CCs

3 Committed as much as other CCs

4 More committed than most CC

5 An exemplar in terms of commitment

Comments 